How Narratives of Racial Progress Create Barriers to Diversity, Equity, and Inclusion in Organizations

\author{
Michael W. Kraus ${ }^{1,2}$, Brittany Torrez ${ }^{1}$, and LaStarr Hollie ${ }^{3}$ \\ ${ }^{1}$ Yale University, School of Management \\ ${ }^{2}$ Yale University, Department of Psychology \\ ${ }^{3}$ University of Massachusetts, Amherst
}

\begin{abstract}
Author Note
This research was supported in part by a grant from the Russell Sage Foundation (RSF \#G-190516246) awarded to MWK. Correspondence concerning this article should be addressed to Michael Kraus (michael.kraus@yale.edu).
\end{abstract}




\begin{abstract}
Despite recent statements in support of racial justice many organizations fail to make good on their commitments to diversity, equity, and inclusion (DEI). In this review, we describe the role of the narrative of racial progress - which conceives of society as rapidly, naturally, and automatically ascending toward racial equity - in these failures. Specifically, the narrative of racial progress: 1) envisions organizations as race neutral, 2) creates barriers to more complex cross-race discussions about equity, 3) creates momentum for less effective policy change, and 4) reduces urgency around DEI goals. Thus, an effective DEI strategy will involve organizational leaders overcoming this narrative by acknowledging past DEI failures, and, most critically, implementing significant, immediate, and evidence-based structural changes that are essential for creating a more just and equitable workplace.
\end{abstract}

Keywords: Racism; Economic Inequality; Social Psychology; Organizational Psychology 


\section{How Narratives of Racial Progress Create Barriers to Diversity, Equity, and Inclusion in Organizations}

The summer of 2020 saw unprecedented participation in racial justice protests across the US [1], with many organizations making public statements denouncing racism and affirming their commitment to diversity, equity, and inclusion (DEI) [2*]. And yet, a year after those commitments were made public, there has been little measurable change in organizational policy or practice [3]. The inertia around DEI goals is not a new phenomenon; a fact made clear by examining the (lack of) change in the share of Black CEOs of Fortune 500 companies over the last 20 years (Figure 1). Despite representing 13.4 percent of the US population, only four Black Americans currently hold the role of CEO of Fortune 500 companies.

How organizations make such public commitments to DEI goals across time without making good on them involves a complex set of interlocking social, economic, and psychological processes [4*-7]. Here we focus on the narrative of racial progress as one potentially powerful framework for understanding these dynamics [8]. Specifically, members of the workforce, much like members of American society, adhere to beliefs that racial equality will naturally unfold across time, and it is this belief in the automatic unfolding of racial progress that makes actual organizational policy change in the service of DEI more unlikely to be competently executed. 


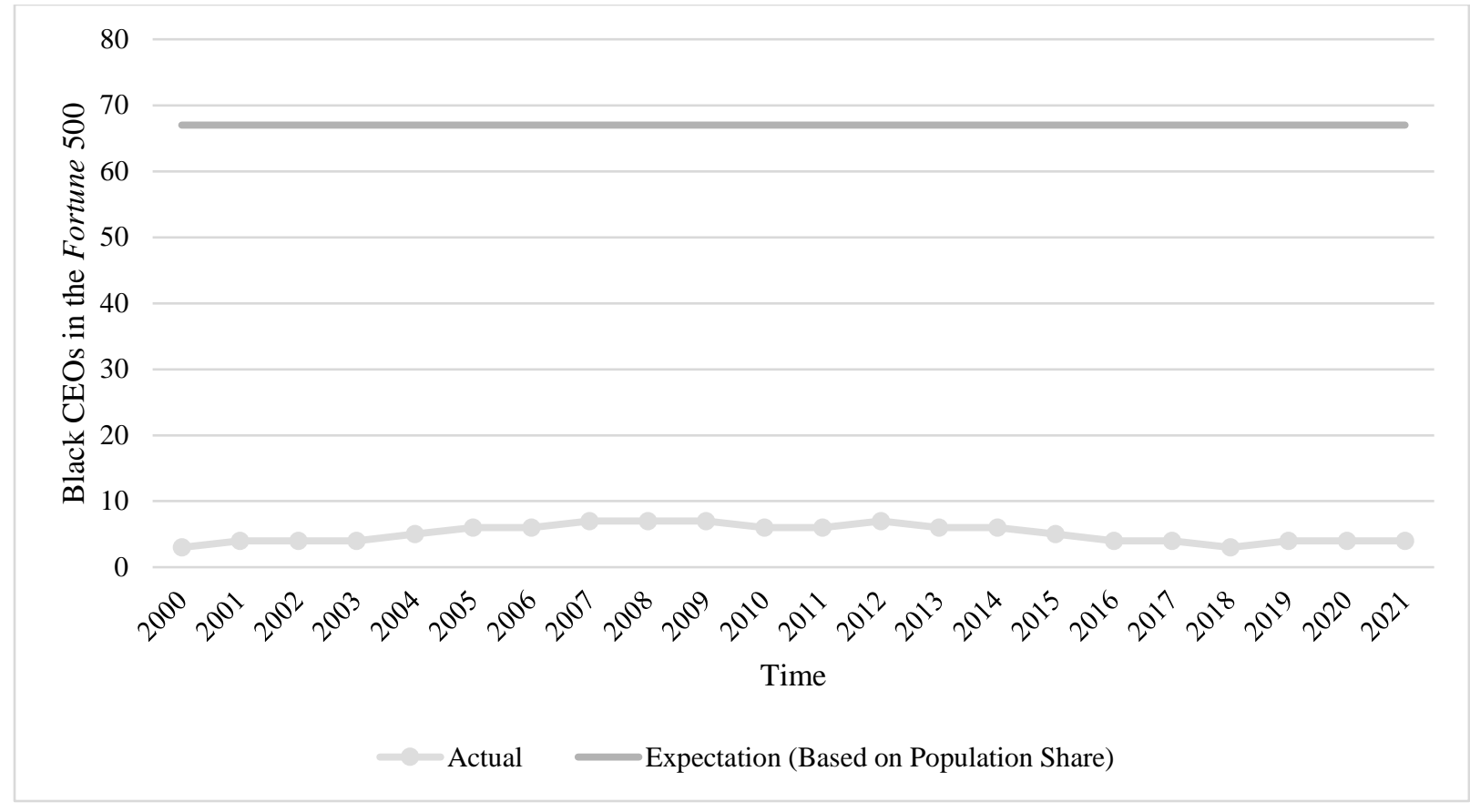

Figure 1. The actual versus expected number of Black CEOs in the Fortune 500 based on population share according to the 2010 US Census.

\subsection{The American Narrative of Racial Progress}

The American narrative of racial progress fundamentally shapes our understanding of both the magnitude and trajectory of racial inequality in society [7,9]. This narrative envisions America as a country continually trending toward justice and equity. As such, the narrative is appealing in that it conceives of a nation most would want to live within while simultaneously minimizing contemporary societal racial inequality [8*]. This minimization highlights the capacity for individuals to achieve their goals irrespective of their racial identities, while conceiving of racial inequality as something that is rapidly, and perhaps naturally, decreasing over time [10-11].

Evidence indicates that this narrative governs judgments of societal and organizational racial equity. American respondents across surveys tend to believe that society has progressed 
toward greater racial equality across financial outcomes that include employer-provided health benefits, wages, income, and wealth at a pace that far exceeds trends measured by federal government data $[8,12-14]$. This tendency to adhere to the narrative of racial progress is widespread in American society according to recent surveys: In the largest survey of these misperceptions of progress toward racial equality, a nationally representative sample of American adults estimated Black family wealth for every $\$ 100$ US held by White families across 12 time points. Across estimates, 97 percent of respondents overestimated the wealth gap between Black and White Americans by some amount (see Figure 2) [8]. Critically, the inaccuracy of estimates increased over time such that respondents estimated that, for every $\$ 100$ US held by White families, Black family wealth was close to \$50 US in 1963 and \$90 US in 2016. In reality, according to the Survey of Consumer Finances, median Black family wealth has never risen above \$13 US for every $\$ 100$ US held by White families [8, 15]. 


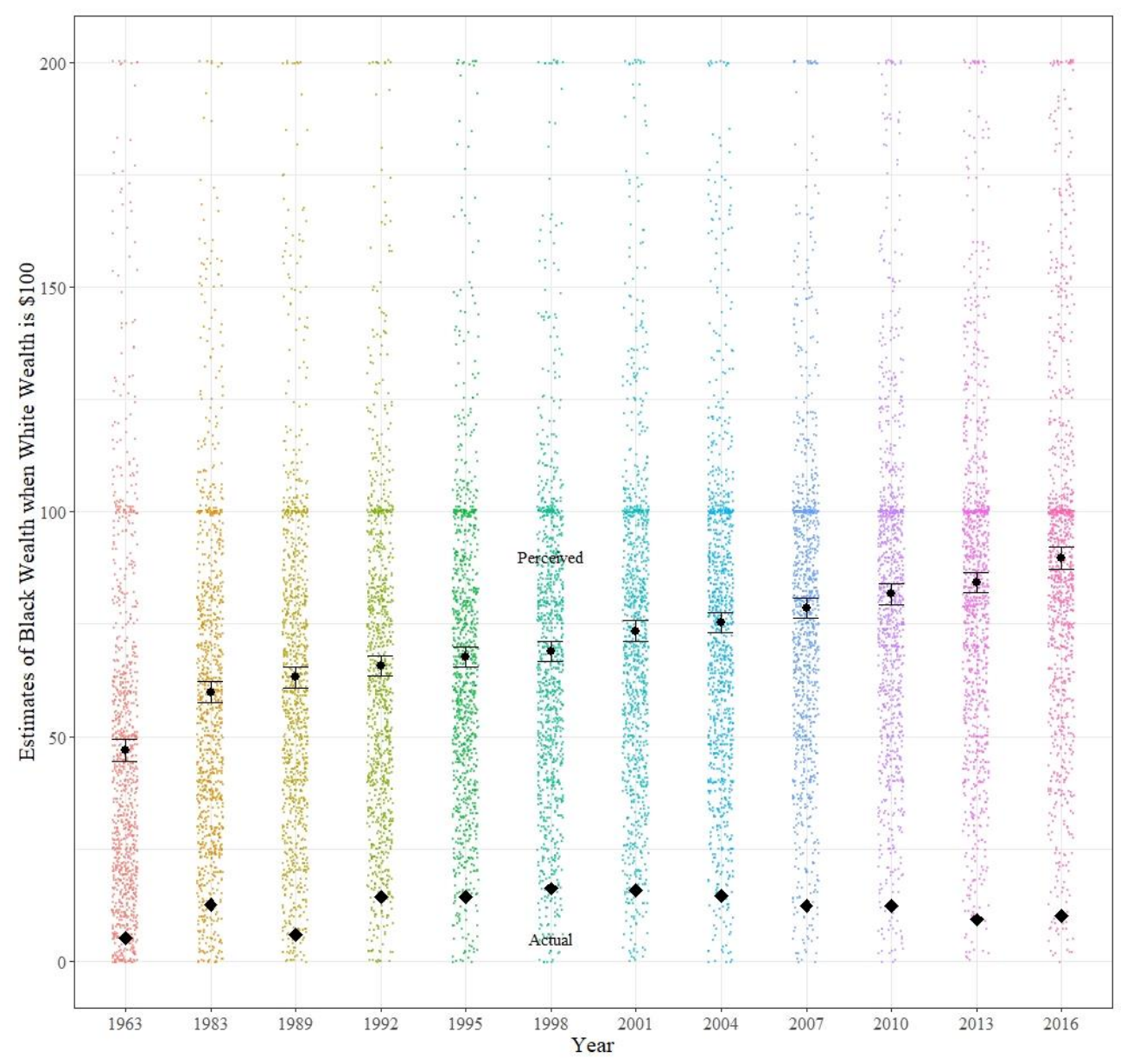

Figure 2. Underestimates of the Black-White wealth gap from 1963 to 2016 where each of the smaller dots indicates one respondent's estimate at each of the twelve time points. The larger dots represent mean respondent estimates of Black wealth when White wealth is set to \$100 US across twelve time points. The diamonds represent actual median Black wealth when White wealth is set to $\$ 100$ US, calculated using federal data from the Survey of Consumer Finances [15]. Error bars indicate $95 \%$ confidence intervals around the mean estimate. This figure is reproduced from Kraus et al., (2019) [8].

\subsection{DEI Progress and Pitfalls}


The widespread presence of the narrative of racial progress across American society means that members of the workforce will adhere to this narrative, at least to some extent, at all levels of status and experience. We anticipate four consequences of adherence to this narrative that can limit progress toward DEI goals: 1) that this narrative fundamentally envisions organizations as race neutral, 2) that it creates barriers to complex, cross-race discussions about equity, 3) that it creates greater momentum for less effective policy changes, and 4) that it reduces urgency around DEI goals. Notably, some firms may not have DEI goals and may instead be ignorant, or even directly hostile, toward efforts to increase diversity [16-17]. This analysis is not focused on these firms because their lack of progress towards DEI goals is more obvious. Instead, we focus here on firms with stated DEI goals, for which there are many, who fail to meet these goals despite their public commitments.

Because the narrative of racial progress envisions a society that is naturally moving towards racial equity, it supports the notion that organizations are race neutral, and that organizational structures play little to no role in the persistence of racism [6]. The assumption of the race neutral organization is fairly common in organizations, but this assumption has never been a reality, as historically underrepresented minoritized workers tend to face exclusion in all facets of the organizational process including in hiring, promotion, voice, and exit [18-19]. Adherence to the narrative of racial progress means that organizations are likely to interrogate evidence of bias, or frame that evidence as an exception to the firm's natural unfolding of justice and equity. In this fashion, the narrative obscures the racialized results of standard practices within an organization. In one example of this process, firms that use extracurricular interests as part of hiring decisions can end up selecting for people of similar interests (e.g., sailing) that then also select for similar racial identities [20]. The narrative of racial progress is likely to lead to a 
downplaying and discounting of these procedures, even as they contribute to hiring bias at the firm.

The narrative of racial progress also creates a barrier to cross-race discussions of equity and justice within organizations. Though the narrative is widespread in American society, motivational and structural forces elicit different distinct patterns of this narrative. Notably, people of color, presumably because of their experiences having to navigate cross-race interactions [21*-22], and their higher likelihood of having socioeconomically diverse social networks [20,23], tend to be more accurate in their estimates of racial inequality in society relative to their White counterparts $[8,13]$. Possessing divergent understandings of the magnitude of racial inequality in society or within a firm, and potentially its causes, means that people of color within the workforce will have several challenges as they advocate for their own inclusion within organizations in discussions with White colleagues. Critically, White workers' estimates of greater racial equality will mean a decreased sense of urgency in efforts to achieve DEI goals among those workers, a process observed in negative White responses to affirmative action policy and practice [24]. In addition, because White workers both overestimate racial equality and tend to be overrepresented in leadership positions within firms, efforts to improve DEI within organizations may start with attempts to measure the level and severity of that inequity, instead of from the assumption that such inequity is designed into the society that the organization exists within [5,10], and the organization itself [6].

As organizations seek to enact DEI goals, they make choices about the magnitude of DEI-related institutional change. The assumption that racial equity will naturally unfold across time creates greater momentum for less radical, and more incremental policy change. In essence, if we can rely on the passage of time to solve our DEI problems, then more radical policy 
changes, requiring fundamental changes to organizational procedure and structure, are more likely to be seen as risky and less likely to develop support from policymakers. Thus, managers will be less in favor of radical structural changes and more likely to prioritize the benefits of incremental policies, even when those policies have little to no apparent benefit to workers' everyday experiences. For example, annual bias training programs are a part of virtually all Fortune 500 companies [25]. A company may be especially likely to adopt an annual bias training program because such programs are cheap, easy to implement, and allow for legal protection in lawsuits about job discrimination [26]. However, in comparison to comprehensive structural changes, like the reorganization of hiring practices to prioritize DEI goals, firms are more likely to commit to the quick-fix-training approach, despite the empirical effectiveness of such restructuring practices [27]. The narrative also makes the lack of evidence for annual bias training programs less concerning to managers - if racial equity unfolds naturally over time, then there is no reason to empirically scrutinize the (lack of) effectiveness of bias training programs in the manner that organizations test and analyze other policy changes.

Resistance to DEI goals is common given power maintenance behaviors exhibited by dominant group members [28-29]. In line with these processes, a belief in the automatic and natural unfolding of racial progress will reduce urgency within firms around DEI goals. If workers believe organizations will naturally diversify across time, then demands for immediate change will be met with calls for calm, caution, and measured action [30]. In essence, workers looking to change fundamental operations within organizations for DEI goals in more immediate ways, including the swift assignment of significant budgetary resources to these goals, are likely to be met with resistance as these actions are envisioned as abrupt. Prior research indicates that DEI goals are likely to be met with backlash to the extent that organizational actors believe that 
equity has already been achieved [31]. Thus, narratives of racial progress fuel backlash, particularly regarding more immediate changes to organizations in the service of DEI.

\subsection{Overcoming the Narrative of Racial Progress}

To this point, we have argued that the narrative of racial progress lays a foundation that fundamentally sabotages organizational goals for DEI because it expects time, and not changes to policy, to do the work of justice and equity. Overcoming this narrative, given its position in public consciousness, and its adherence in American society, is a significant challenge.

Nevertheless, that many firms already have very public commitments to DEI goals suggests that some organizations and their leaders have a commitment to these goals, and simply do not know what it takes to achieve them.

To overcome the narrative and begin to make actual progress, organizations must become familiar with their track record on DEI goal achievements across time. By and large, most firms do not make progress toward their DEI goals but are not fully aware of this track record given adherence to these narratives $[8,11]$. A careful review of the history of failure to create DEI gains will help firms recalibrate to all the processes and changes that have been tried (and failed) over the history of the organization and its leadership. Confronting these real, and predictable, trends in organizational failure is a necessary precondition to developing an effective DEI strategy.

Beyond acknowledgment of past failure in enacting DEI goals, a common problem in the context of understanding racial inequality is the expectation that individual levels of application of effort, skill, and talent will be sufficient to overcome deeply rooted institutional structural barriers to DEI [32]. In essence, many firms expect minoritized members of the workforce to overcome, without assistance or reward, decades of scarce management diversity and racist organizational practices, that encompass everything from hiring practices to dress code rules 
[33*]. This pattern reflects a general societal understanding of racial inequality, which prioritizes individual agency over structural policy as the primary driver of that inequality [34]. Truly discarding the narrative of racial progress means acknowledging that organizational policies, even policies that have resulted in monetary successes for the organization, have come at the expense of DEI goals, and that new, more equitable, policies must be enacted to transform the firm's norms and practices.

The matter of how to identify new policy has been well studied and articulated in other research $\left[27,35^{*}\right]$. Critically, the DEI policies that tend to have more success involve making direct (and costly) structural changes to organizational operations, including mentorship networks and hiring outreach programs [27]. Overcoming the narrative of racial progress can be as straightforward as investing in, and then actually executing, structural changes within an organization that are backed by a clear evidence base for positive change toward diversity, equity, and inclusion [36-37].

\subsection{Conclusion}

Confronting racial inequity within society and organizations requires us to acknowledge that our world is designed to be unequal from the beginning, and that time and patience will not be sufficient to change that design. Instead, organizations must overcome narratives that conceive of racial equality as naturally and automatically unfolding over time, and instead envision diversity, equity, and inclusion as a process of structural change that relies on evidencebased policies that fundamentally change the nature of organizations and their internal processes. We cannot have the truly equitable and inclusive workplace that we desire before confronting the inequitable and exclusive workplace we currently reside within. 


\section{References}

1. Buchanon, B., Bui, Q, \& Patel, J. K. (2020). Black Lives Matter may be the largest movement in US history. New York Times.

https://www.nytimes.com/interactive/2020/07/03/us/george-floyd-protests-crowd-size.html

2. Ray, V. (2020). Antiracism is a Constant Struggle. Contexts, 19(3), 74-76.

*This article summarizes the challenges inherent in creating organizations with racial equity and how such organizations require constant force in the direction of equity to be successful in their DEI goals.

3. Quiroz-Gutierrez, M. (2021). American companies pledged $\$ 50$ billion to Black communities. Most of it hasn't materialized. Fortune. https://fortune.com/2021/05/06/uscompanies-black-communities-money-50-billion/

4. Kraus, M. W., \& Torrez, B. (2020). A psychology of power that is embedded in societal structures. Current opinion in psychology, 33, 86-90.

*This article conceptualizes power in a collective sense, embedded in societal structures, such as racism. Understanding power in this structural context has implications for how organizations approach DEI goals, and critically, whether they take on the necessary structural reorganizations to enact those goals.

5. Mills, C. W. (2014). The racial contract. Cornell University Press.

6. Ray, V. (2019). A theory of racialized organizations. American Sociological Review, 84(1), 26-53.

7. Richeson, J. A. (2020). Americans are determined to believe in Black progress. The Atlantic. 
8. Kraus, M. W., Onyeador, I. N., Daumeyer, N. M., Rucker, J. M., \& Richeson, J. A. (2019). The misperception of racial economic inequality. Perspectives on Psychological Science, 14(6), 899-921.

*This article summarizes the psychological components that underlie beliefs in racial progress and overestimates of racial equality. Both motivational and informational circumstances conspire to produce a tendency to believe that racial progress is natural, automatic, and likely in the future.

9. Bell, D. (1993). The racism is permanent thesis: Courageous revelation or unconscious denial of racial genocide. Cap. UL Rev., 22, 571.

10. Mueller, J. C. (2020). Racial ideology or racial ignorance? An alternative theory of racial cognition. Sociological Theory, 38(2), 142-169.

11. Seamster, L., \& Ray, V. (2018). Against teleology in the study of race: Toward the abolition of the progress paradigm. Sociological Theory, 36(4), 315-342.

12. DeBell, M. (2017). Polarized opinions on racial progress and inequality: Measurement and application to affirmative action preferences. Political Psychology, 38(3), 481-498.

13. Kraus, M. W., Rucker, J. M., \& Richeson, J. A. (2017). Americans misperceive racial economic equality. Proceedings of the National Academy of Sciences, 114(39), 10324-10331.

14. Kraus, M. W., Hudson, S.T.J., \& Richeson, J.A (in press). Framing, Context, and the Misperception of Black-White Wealth Inequality. Social Psychological and Personality Science.

15. Bricker, J., Dettling, L. J., Henriques, A., Hsu, J. W., Jacobs, L., Moore, K. B., ... \& Windle, R. A. (2017). Changes in US family finances from 2013 to 2016: Evidence from the Survey of Consumer Finances. Fed. Res. Bull., 103, 1. 
16. Kteily, N., Bruneau, E., Waytz, A., \& Cotterill, S. (2015). The ascent of man: Theoretical and empirical evidence for blatant dehumanization. Journal of personality and social psychology, 109(5), 901.

17. Kteily, N. S., \& McClanahan, K. J. (2020). Incorporating insights about intergroup power and dominance to help increase harmony and equality between groups in conflict. Current opinion in psychology, 33, 80-85.

18. Bertrand, M., \& Mullainathan, S. (2004). Are Emily and Greg more employable than Lakisha and Jamal? A field experiment on labor market discrimination. American economic review, 94(4), 991-1013.

19. Tomaskovic-Devey, D., Zimmer, C., Stainback, K., Robinson, C., Taylor, T., \& McTague, T. (2006). Documenting desegregation: Segregation in American workplaces by race, ethnicity, and sex, 1966-2003. American sociological review, 71(4), 565-588.

20. Rivera, L. A. (2015). Pedigree: How elite students get elite jobs. Princeton University Press.

21. Dupree, C. H., \& Fiske, S. T. (2019). Self-presentation in interracial settings: The competence downshift by White liberals. Journal of Personality and Social Psychology, 117(3), 579.

*This article provides evidence suggesting liberal and White interaction partners in interracial settings downshift competence in how they speak to racial minorities. This social interaction process is conceptually related to how organizations, intending to enact DEI goals, fail to enact these goals in favor of reducing the social discomfort that comes with change. 
22. Richeson, J. A., \& Shelton, J. N. (2007). Negotiating interracial interactions: Costs, consequences, and possibilities. Current Directions in Psychological Science, 16(6), 316320.

23. Pattillo, M. (2013). Black picket fences: Privilege and peril among the black middle class. University of Chicago Press.

24. Lowery, B. S., Unzueta, M. M., Knowles, E. D., \& Goff, P. A. (2006). Concern for the ingroup and opposition to affirmative action. Journal of personality and social psychology, 90(6), 961.

25. Chang, E. H., Milkman, K. L., Zarrow, L. J., Brabaw, K., Gromet, D. M., Rebele, R., ... \& Grant, A. (2019). Does Diversity Training Work the Way It's Supposed To?. Harvard Business Review. https://hbr.org/2019/07/does-diversity-training-work-the-way-its-supposedto

26. Chang, E. H., Kirgios, E. L., \& Smith, R. K. (2021). Large-scale field experiment shows null effects of team demographic diversity on outsiders' willingness to support the team. Journal of Experimental Social Psychology, 94, 104099.

27. Kalev, A., Dobbin, F., \& Kelly, E. (2006). Best practices or best guesses? Assessing the efficacy of corporate affirmative action and diversity policies. American sociological review, 71(4), 589-617.

28. Dovidio, J. F., \& Gaertner, S. L. (1986). Prejudice, discrimination, and racism. Academic Press.

29. Sears, D. O., \& Henry, P. J. (2003). The origins of symbolic racism. Journal of personality and social psychology, 85(2), 259. 
30. Syed, M. (2021). The Logic of Microaggressions Assumes a Racist Society.

\section{https://psyarxiv.com/4ka37/}

31. Brannon, T. N., Carter, E. R., Murdock-Perriera, L. A., \& Higginbotham, G. D. (2018). From backlash to inclusion for all: Instituting diversity efforts to maximize benefits across group lines. Social issues and policy review, 12(1), 57-90.

32. Rucker, J., Duker, A., \& Richeson, J. (2019). Structurally unjust: How lay beliefs about racism relate to perceptions of and responses to racial inequality in criminal justice.

\section{https://psyarxiv.com/sjkeq/}

33. Kim, J. Y., Fitzsimons, G. M., \& Kay, A. C. (2018). Lean in messages increase attributions of women's responsibility for gender inequality. Journal of Personality and Social Psychology, 115(6), 974.

*This article provides one example of how organizations typically force workers to adjust in order to make progress on DEI goals. Importantly, individual worker adjustments create an additional burden on workers.

34. McCall, L., Burk, D., Laperrière, M., \& Richeson, J. A. (2017). Exposure to rising inequality shapes Americans' opportunity beliefs and policy support. Proceedings of the National Academy of Sciences, 114(36), 9593-9598.

35. Onyeador, I. N., Hudson, S. K. T., \& Lewis Jr, N. A. (2021). Moving beyond implicit bias training: Policy insights for increasing organizational diversity. Policy Insights from the Behavioral and Brain Sciences, 8(1), 19-26.

*This article summarizes the many policy changes organizations can enact to make good on their DEI objectives. Critically, the article highlights some of the planning and coordination necessary to reduce the reactance of dominant group members. 
36. Carter, E. R., Onyeador, I. N., \& Lewis Jr, N. A. (2020). Developing \& delivering effective anti-bias training: Challenges \& recommendations. Behavioral Science \& Policy, 6(1), 57-70.

37. Dupree, C. H., \& Boykin, C. M. (2021). Racial inequality in academia: Systemic origins, modern challenges, and policy recommendations. Policy Insights from the Behavioral and Brain Sciences, 8(1), 11-18. 